\title{
One-step prepectoral breast reconstruction with porcine dermal matrix-covered implant: a protective technique improving the outcome in post-mastectomy radiation therapy setting
}

\author{
Susanna Polotto ${ }^{1}$, Maria Luisa Bergamini ${ }^{2}$, Giuseppe Pedrazzi ${ }^{3}$, Maria F. Arcuri ${ }^{1}$, Francesca Gussago ${ }^{1}$, \\ Leonardo Cattelani ${ }^{1}$ \\ ${ }^{1}$ Breast Surgical Unit, University Hospital of Parma, Parma (PR), Italy; ${ }^{2}$ Radiotherapy Unit, University Hospital of Parma, Parma (PR), Italy; \\ ${ }^{3}$ Neuroscience Unit, Department of Medicine and Surgery, University of Parma, Parma (PR), Italy \\ Contributions: (I) Conception and design: L Cattelani, S Polotto; (II) Administrative support: S Polotto; (III) Provision of study materials or patients: \\ S Polotto, ML Bergamini; (IV) Collection and assembly of data: S Polotto; (V) Data analysis and interpretation: S Polotto, G Pedrazzi; (VI) \\ Manuscript writing: All authors; (VII) Final approval of manuscript: All authors. \\ Correspondence to: Leonardo Cattelani, MD. Breast Surgical Unit, University Hospital of Parma, Via Gramsci 14, 43125 Parma (PR), Italy. \\ Email: cattelanil@hotmail.com.
}

Background Post-mastectomy radiotherapy (PMRT) applied on implant-assisted immediate breast reconstruction (IBR) involves a marked increase in complication rate. The recent opportunity of performing an $\mathrm{ADM}$-assisted prepectoral breast reconstruction (PPBR) raised the hypotesis of a protective interaction between ADM and periprosthetic tissues under PMRT.

Methods: We performed a retrospective monocentric analysis of a cohort of consecutively treated patients undergone one-step PPBR between January 2015 and September 2018. The aim is to examine complication rate and aesthetic satisfaction of patients, in order to evaluate if this reconstructive technique could be recommendable in PMRT setting. Group 1 comprised 158 patients not submitted to PMRT and Group 2 twenty-eight patients undergone PMRT.

Results: All post-operative complications were not statistically different between the two groups, except for capsular contracture $(\mathrm{P}=0.011)$. We obtained very high percentages in all BREAST-Q categories in Group 2 patients: satisfaction with breasts $86.8 \pm 13.9$, satisfaction with implants $6.5 \pm 3.0$, high satisfaction for no adverse effects of radiation $15.7 \pm 6.8$. According to multivariate analysis no risk factor was significantly associated with complications.

Conclusions: We may conclude that one-step PPBR with porcine ADM followed by PMRT is well tolerated, with no significant risk of adverse outcomes, at least in the short-term follow-up. These promising outcomes warrant further studies to examine the existence of a protective effect due to ADM integration with subcutaneous tissue.

Keywords: Immediate breast reconstruction (IBR); prepectoral breast reconstruction; breast radiation therapy

Submitted Sep 24, 2019. Accepted for publication Jan 04, 2020.

doi: 10.21037 /gs.2020.01.16

View this article at: http://dx.doi.org/10.21037/gs.2020.01.16 


\section{Introduction}

Immediate breast reconstruction (IBR) after mastectomy represents the optimal approach to better preserve selfestimation and psychosocial well-being of patients (1). During the last two decades, one-stage direct-toimplant (DTI) reconstruction gained widespread use (2). Simultaneously, post-mastectomy radiotherapy (PMRT) registered expanded indications with the purpose of eliminate microscopic residual disease in the loco-regional area. PMRT is associated with a decrease in local recurrence and an improvement in overall survival among patients with high-risk pathologic features (tumour $>5 \mathrm{~cm}$, positive lymph nodes, positive margins) (3). On the other side, radiation therapy leads to undesired effects on healthy tissues with detrimental effects over implant-based IBR with a marked increase in rate of both precocious and long-term major complications and failures (4-6).

Berry and colleagues reported that PMRT determined a doubled risk of major complications and a $30 \%$ of implant loss (7); Jhaveri found that, in such patients, aesthetic acceptable results were only $51 \%$ (8). According to recent reviews, the incidence of Spear-Baker grade III and IV capsular contracture after PMRT increased up to $43 \%$ from a $5 \%$ in non-radiated patients (9-11), leading to unplanned subsequent revisionary surgery in $25 \%$ of patients (12).

The relevant number of reconstruction failures in PMRT setting leaded some authors to opt for a delayed flapbased reconstruction $(10,11,13,14)$. Finally, the indication for PMRT sometimes derives from a multidisciplinary discussion on histologic data available only after surgery, when an implant-based IBR has already been done.

In the last 5 years, a complete prosthetic coverage with $\mathrm{ADM}$ allowed inaugurating the subcutaneous prepectoral breast reconstruction (PPBR); this technique gained fast popularity for its muscle-conserving character and the natural shape of reconstructed breast. Apart from its excellent aesthetic and functional results, this new procedure appeared less burdened by grade III and IV capsular contracture (15-17).

In the meantime, some patients with ADM-assisted PPBR underwent PMRT and the great majority of them did not suffer of any foreseen adverse effect, raising the postulate of a true protective interaction between ADM and periprosthetic tissues (18-20).

The hypothesis that PPBR with porcine ADM-wrapped implant could better tolerate PMRT injuries need to get over the anecdotal remark and deserves a statistically structured investigation. The aim of our study is to assess whether ADM-assisted PPBR might represent an improvement in IBR successively submitted to radiation therapy and to evaluate if this technique could be a recommendable reconstructive procedure in this setting.

\section{Methods}

We retrospectively analysed a series of patients consecutively treated with one-step PPBR performed in our unit from January 2015 to September 2018. The research protocol of the study was approved by the local Ethics Committee and patients gave written informed consent. Patients were divided in two groups: Group 1 comprised 158 patients (174 reconstructed breasts) who were not submitted to PMRT; Group 2 was composed by 28 patients (28 breasts) undergone PMRT. Twentyfour patients undergone $3 \mathrm{D}$ conformation radiation therapy (3DCRT) and four undergone Volumetric Modulated therapy (VMAT). Between the 24 patients of the 3DCRT subgroup, 16 were treated on the chest wall and supraclavicular lymph nodes, seven on the chest wall and only one on the lymph-nodal stations (supraclavicular nodes). In the VMAT subgroup three were treated on the chest wall and loco-regional lymph nodes (supraclavicular, infraclavicular, inframammary and axillary nodes), none on the chest wall and only one on the lymph nodal stations (supraclavicular, infraclavicular, inframammary and axillary nodes). We respected the following inclusion criteria: patients with breast tumour undergone nipple or skinsparing mastectomy associated to immediate PPBR with definitive implant, no previous radiation therapy, age $<85$ years, TNM stage $<\mathrm{IV}$, no active smokers in the last month, no significant comorbidities (diabetes, obesity, autoimmunity disease, etc.). A member of the surgical team analysed age, body mass index (BMI), minor comorbidities, neo-adjuvant or adjuvant chemotherapy, adjuvant radiation therapy, uni- or bilateral procedures, implant volume, immediate and late complications (implant infection, pocket seroma or hematoma, wound dehiscence, skin necrosis, implant loss, grade III or IV of Baker scale capsular contracture, rippling), local cancer recurrence, secondary procedures (i.e., lipofilling, remodelling of reconstruction), contralateral symmetrisation. She also analysed patients' aesthetic satisfaction through BREAST-Q Questionnaire, administered routinely 6 months after surgery in patients not undergone PMRT and 6 months after completion of radiation therapy in those undergone PMRT. All PPBR 
were performed with textured anatomical silicone gel implants (Allergan Natrelle ${ }^{\circledR}$ and Mentor ${ }^{\circledR}$ Worldwide LLC, Irvine, CA, USA) completely wrapped with porcine derived Braxon $^{\circledR} \mathrm{ADM}$ (Decomed, Venice, Italy).

\section{Surgical technique}

After nipple- or skin-sparing mastectomy associated with sentinel lymph node biopsy or complete axillary lymph node dissection, the reconstructive phase consisted in total wrapping of an anatomic silicone implant with the Braxon ${ }^{\circledR}$ device, a pre-shaped porcine not-cross-linked ADM $0.6 \mathrm{~mm}$ thick, after a rehydration in physiologic solution for 5 minutes. We usually fix inferomedially the edges of the wrapped implant to the pectoralis major fascia by 3-0 absorbable interrupted stitches to maintain the implant in the correct position. We put some other absorbable stitches between the ADM and the subcutaneous tissue in the upper and lateral breast region to obliterate dead space and promote ADM integration. Finally, we insert a closedsuction drain along the inframammary fold and close the skin in layers.

\section{Radiation therapy planning}

To determine the optimal radiation technique, we evaluate patient anatomy, target volume and dose constraints. A description of the two radiation techniques utilized in our group of patients is detailed below.

\section{D conformation radiation therapy (3DCRT)}

The most commonly used treatment for PMRT in our centre is the 3DCRT, a forward-planned technique utilizing photons. We use 3 to 5 beams to treat the chest wall and regional lymph nodes. We treat the chest wall with two opposing tangential fields and the supraclavicular lymph nodes volumes with a single anterior field. We can adjust the energy of the beam so that the 44 Gray (Gy) line reaches to the posterior edge of the lymph node volumes.

\section{Intensity-modulated radiation therapy (IMRT)}

We perform IMRT when dose-volume constraints of organs at risk with 3DCRT planning are not met. IMRT is an inverse planning technique using photons, typically involving a greater number of beams when compared to 3DCRT. We apply Volumetric Modulated therapy (VMAT) to our patients, a kind of IMRT technique that employs continuous arcs during treatment.

\section{Radiation dosing and fractionation}

Conventional dosing for PMRT in our centre is 4650 Gy in 2.0 Gy per fraction (23-25 total fractions) to the chest wall and 44-46 Gy in 2.0 Gy per fraction (22-23 total fractions) to the regional lymph nodes. Since photons require tissue interaction to build up the dose, the dose at the skin surface is lower than the dose at the target. No skin boost was delivered to patients.

\section{Therapeutic indications for PMRT}

In our study, PMRT is administered to patients with T3N+ or T3N0 tumours based on risk factors, tumours extended to the skin (regardless of the lymph node status), T1-2N2, positive margins. In patients not belonging to the previous categories, with T1-2 and positive lymph nodes $1-3$, radiation therapy is evaluated on the basis of the following risk factors: age $<40-45$ years, tumour $\geq 3.5 \mathrm{~cm}, \mathrm{ER}$ - and PGR-, lymph vascular invasion, G3, nodal ratio $>20-25 \%$. In fact, when these factors are present, local recurrence risk may overcome $20 \%$, negatively affecting overall survival (21-23). We also perform PMRT in non-invasive tumours $>5 \mathrm{~cm}$ and margins $\leq 1 \mathrm{~mm}$ or positive (24-26).

\section{Analysis and statistical methods}

We executed data analysis with statistic packages IBMSPSS v.22, JASP v.0.9.6.6 and R v.3.5.3. For the descriptive analysis of the continuous variables, we calculated standard indexes, such as the mean, median, trimmed mean, variance, standard deviation, quartiles, minimum, maximum, range, asymmetry and kurtosis coefficients, and their standard error and confidence intervals at $95 \%$. Qualitative data, namely categorically mutable, were reported in frequency tables and expressed as absolute, relative, cumulative frequency and percentages.

We examined association between complications and clinical predictors by logistic regression. We considered all results statistically significant for $\mathrm{P}<0.05$.

\section{Results}

We enrolled 186 patients undergone nipple or skin-sparing mastectomy with immediate one-step prepectoral ADMimplant based reconstruction. In Table 1, demographic characteristics of patients are shown. PMRT was applied after a median post-operative period of 142.29 days (range, 60-246 days), depending on adjuvant chemotherapy administration. There is no statistically significant difference 
Table 1 Demographic characteristics of Group 1 and Group 2 (DS: standard deviation)

\begin{tabular}{|c|c|c|c|}
\hline Variables & Group 1 & Group 2 & $P$ value \\
\hline No. of patients & 158 & 28 & \\
\hline No. of breasts & 174 & 28 & \\
\hline Follow-up (months) & & & 0.233 \\
\hline Mean & 24.7 & 21.7 & \\
\hline Median & 20.4 & 20.3 & \\
\hline Min & 10.3 & 6.1 & \\
\hline Max & 60.7 & 46.5 & \\
\hline DS & 12.5 & 11.8 & \\
\hline Age (years) & & & 0.321 \\
\hline Mean & 53.4 & 55.6 & \\
\hline Median & 51.0 & 54.0 & \\
\hline Min & 25.0 & 37.0 & \\
\hline Max & 85.0 & 79.0 & \\
\hline DS & 10.4 & 10.8 & \\
\hline BMI $\left(\mathrm{kg} / \mathrm{m}^{2}\right)$ & & & 0.939 \\
\hline Mean & 23.6 & 23.5 & \\
\hline Median & 23.0 & 23.2 & \\
\hline Min & 17.9 & 19.0 & \\
\hline Max & 34.8 & 30.3 & \\
\hline DS & 3.85 & 3.3 & \\
\hline Smokers, n (\%) & & & 0.36 \\
\hline Yes & $20(12.7)$ & $3(10.7)$ & \\
\hline No & $128(81.0)$ & 25 (89.3) & \\
\hline Ex & $10(6.3)$ & $0(0)$ & \\
\hline Comorbidities, n (\%) & & & 0.315 \\
\hline Yes & $31(19.6)$ & 8 (28.6) & \\
\hline No & $127(80.4)$ & $20(71.4)$ & \\
\hline $\begin{array}{l}\text { Neo-adjuvant } \\
\text { chemotherapy, n (\%) }\end{array}$ & & & 0.05 \\
\hline Yes & $21(13.3)$ & $8(28.6)$ & \\
\hline No & $137(86.7)$ & $20(71.4)$ & \\
\hline $\begin{array}{l}\text { Adjuvant } \\
\text { chemotherapy, n (\%) }\end{array}$ & & & 0.048 \\
\hline Yes & $47(29.8)$ & $14(50.0)$ & \\
\hline No & $111(70.2)$ & $14(50.0)$ & \\
\hline Implant volume (g) & & & 0.946 \\
\hline Mean & 398.2 & 396.8 & \\
\hline Median & 400 & 400 & \\
\hline Min & 190 & 180 & \\
\hline Max & 640 & 580 & \\
\hline DS & 102.4 & 109.2 & \\
\hline
\end{tabular}

between age, BMI, smoke habit and comorbidities in the two groups. Also, the mean volume of implant positioned (398.2 vs. $396.8 \mathrm{~g}, \mathrm{P}$ value $=0.946$ ) and duration of follow-up (mean 24.7 months for Group 1 and 21.7 months for Group $2, \mathrm{P}$ value $=0.233)$ are not statistically different. As expected, Group 2 patients underwent more often neo-adjuvant and adjuvant chemotherapy $(28.6 \%$ vs. $13.3 \%$, $\mathrm{P}$ value $=0.05$ and $50 \%$ vs. $29.8 \%, \mathrm{P}$ value $=0.048)$. Between postoperative complications, we observed in particular $5.2 \%$ of implant infections in Group 1 vs. 0\% in Group 2, 8.0\% late seroma in Group 1 vs. 7.1\% in Group 2, 0.6\% hematoma in Group 1 vs. 0\% in Group 2, 2.9\% wound dehiscence in Group 1 vs. 0\% in Group 2, 1.1\% implant loss in Group 1 vs. 3.6\% in Group 2, $0.6 \%$ capsular contracture in Group 1 vs. $10.7 \%$ in Group 2. All the above-mentioned complications and other examined are not statistically significant between the two groups, except for capsular contracture $(\mathrm{P}=0.011)$ (Table 2).

We applied BREAST-Q to all patients except for three patients in whom reconstruction failed (two in Group 1 and one in Group 2). In Group 1 BREAST-Q was applied 6 months after completion of reconstruction and in Group 2 six months after completion of radiation therapy. As shown in Table 3, we obtained better satisfaction with breasts in Group 1 (94.3 vs. 86.8, $\mathrm{P}$ value $<0.001$ ), high percentages in psychosocial and physical well-being in both groups (93.5 vs. 91.7 and 94.0 vs. 92.9), better sexual well-being in Group 1 (81.9 vs. 69.1, P value <0.001), high percentages in satisfaction with information and with staff in both groups, high percentages in satisfaction with implants in both groups $(7.3$ vs. $6.5, \mathrm{P}$ value $=0.065)$, high satisfaction for no adverse effects of radiation in Group $2(15.7 \pm 6.8)$ (Figure 1). According to statistician, not applying BREAST-Q to three patients does not alter the statistical significance.

We performed multivariate analysis in order to assess the correlation between some risk factors (radiation therapy, age, BMI, comorbidity, smoking status, implant volume, adjuvant or neo-adjuvant chemotherapy) and complication rate observed. No risk factor influences on complication rate, except for implant volume that was close to statistical significance $(\mathrm{P}$ value $=0.072)$.

\section{Discussion}

At present, implant-based reconstruction represents the most common method to restore breast mound after nipple or skin sparing mastectomy (27). At the same time, PMRT increases its indications, adversely affecting reconstruction results. 
The American College of Radiology recommends PMRT for tumours $>5 \mathrm{~cm}$ or with $>$ four axillary lymph nodes involved but it is applied also in certain high-risk pathologic patterns (28,29). Moreover, the Early Breast Cancer Trialists' Collaborative Group (EBCTCG) performed a meta-analysis pooling patient data from 22 randomized trials comparing mastectomy and IBR associated or not with PMRT, and found out that PMRT reduced loco regional cancer recurrence by $19 \%$ which translated into a $9 \%$ reduction in breast cancer mortality (30).

Table 2 Post-operative complications of Group 1 and Group 2 (DS: standard deviation)

\begin{tabular}{lccc}
\hline Complications & Group 1 (n=174) Group 2 (n=28) P value \\
\hline Infection, n (\%) & $9(5.2)$ & $0(0)$ & 0.359 \\
Seroma, n (\%) & $14(8.0)$ & $2(7.1)$ & 0.999 \\
Hematoma, n (\%) & $1(0.6)$ & $0(0)$ & 0.999 \\
Wound dehiscence, n (\%) & $5(2.9)$ & $0(0)$ & 0.999 \\
Skin necrosis, n (\%) & $0(0)$ & $0(0)$ & 0.999 \\
Implant loss, n (\%) & $2(1.1)$ & $1(3.6)$ & 0.389 \\
Capsular contracture, & $1(0.6)$ & $3(10.7)$ & 0.011 \\
$\mathrm{n}(\%)$ & & & \\
Rippling, n (\%) & $1(0.6)$ & $0(0)$ & 0.999 \\
Other, n (\%) & $2(1.1)$ & $0(0)$ & 0.999 \\
Antibiotic therapy, n (\%) & $11(6.3)$ & $0(0)$ & 0.376 \\
\hline
\end{tabular}

Target volume should include the chest wall and involved lymph node areas (axillary, supraclavicular, infraclavicular and internal mammary lymph nodes). If all lymph nodes are negative and the patient has a positive margin, then PMRT can be delivered only to the chest wall.

Radiation therapy represents one of the most serious risk factors for major complication in implant-based breast reconstruction (31). Radiation-induced acute toxicity occurs within 3 months of radiation treatment. The most common adverse effect is radiation dermatitis that may culminate in intensity one to two weeks after the end of radiation therapy. This side effect may lead to reconstructed breast complications such as wound dehiscence, implant infection, late seroma (32). PMRT associated chronic toxicity includes hyperpigmentation and tissue fibrosis affecting cosmetic and functional outcome of breast reconstruction and may lead to progressive muscle fibrosis and atrophy associated to dermal thickening (33).

Because of radiation damage, PMRT is associated with increased rates of significant capsular contracture, implant loss, revision surgeries, and overall worse cosmetic outcomes (34). The timing of the breast reconstruction (i.e., immediate $v s$. delayed) and type of breast reconstruction (i.e., autologous $v s$. implant-based) are important considerations that require an informative discussion with the patient before surgery. However, sometimes radiation therapy is decided post-operatively, based on definitive histologic result when breast reconstruction has already been

Table 3 BREAST- $\mathrm{Q}^{\mathrm{TM}}$ results

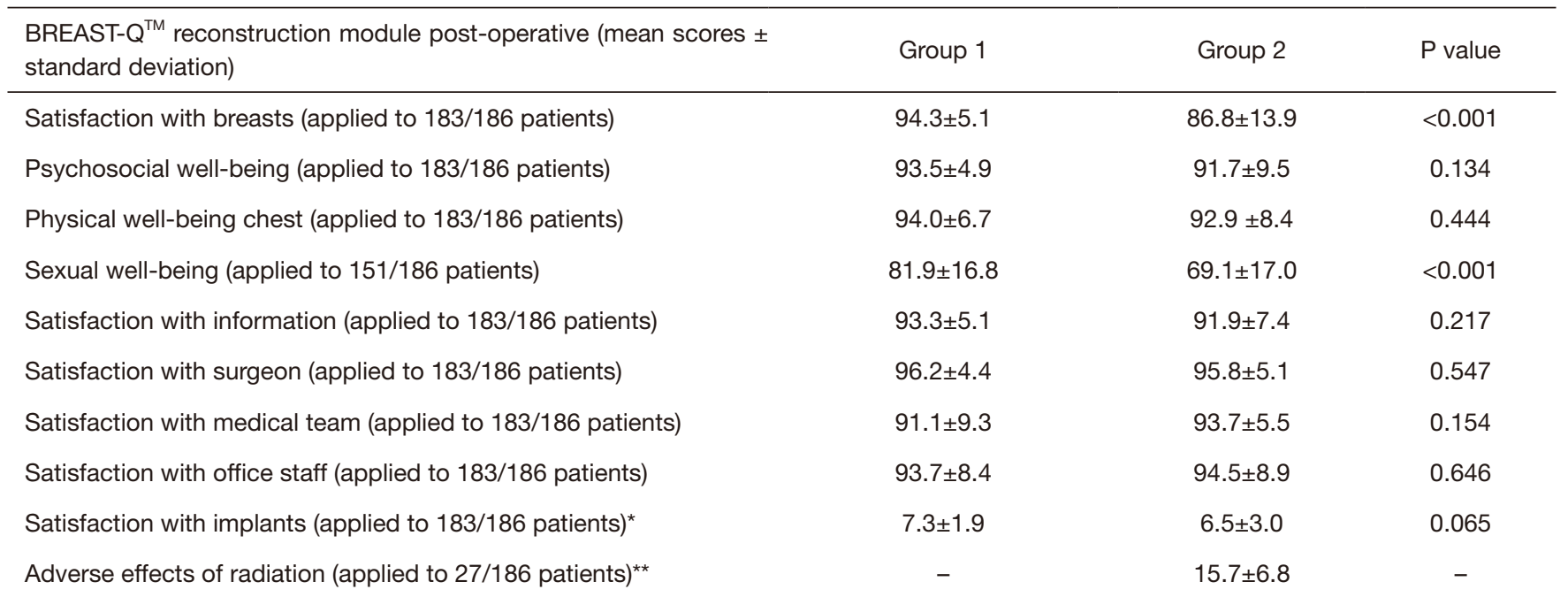

${ }^{*}$ and ${ }^{* *}$ : these sections of the questionnaire should be considered as stand-alone. Higher scores reflect a better outcome $\left({ }^{*}\right.$ scores go from a minimum of 2 to a maximum of 8 ; ${ }^{* *}$ scores go from a minimum of 6 to a maximum of 18 ). 

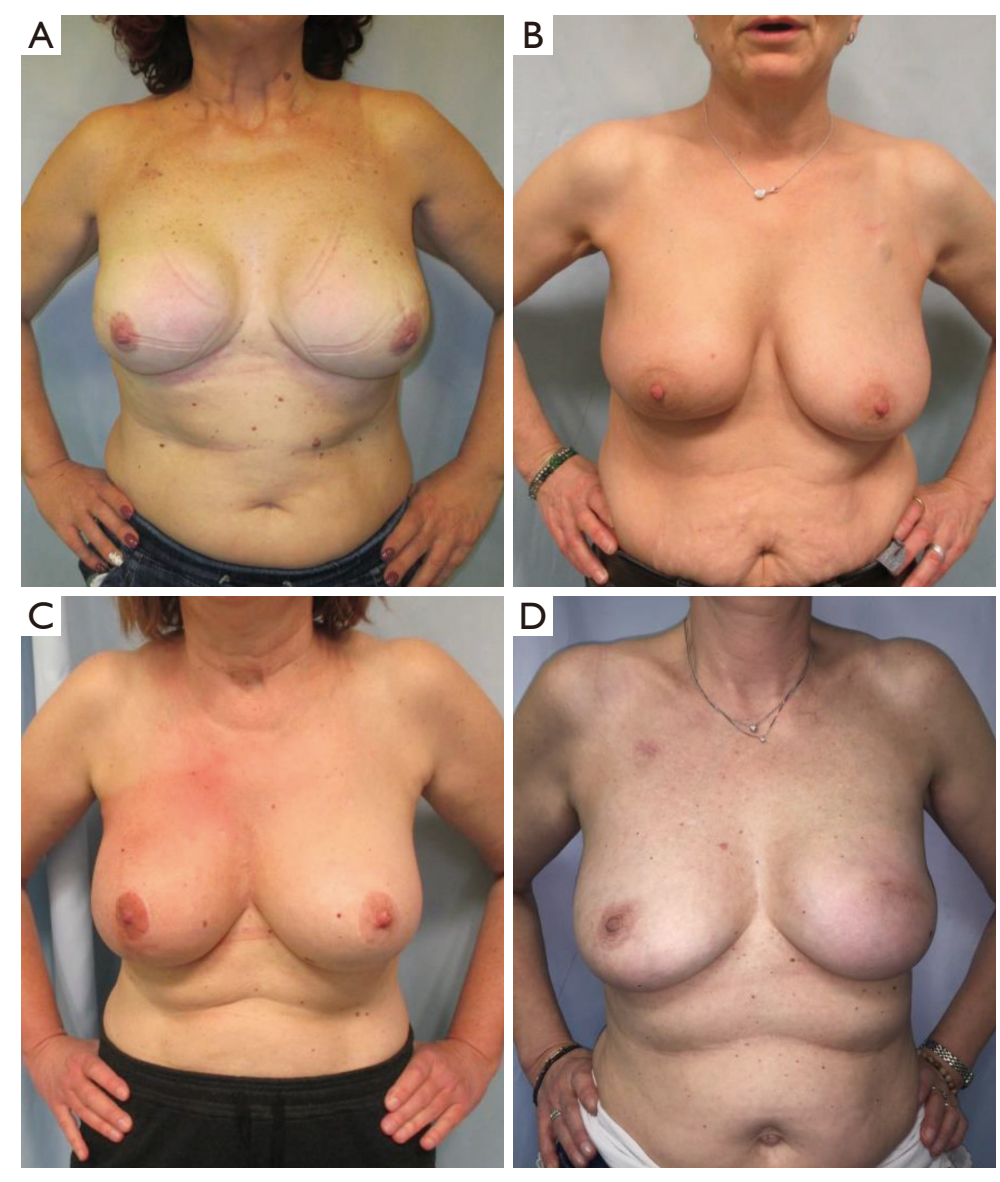

Figure 1 Examples of post-operative results of immediate ADM-assisted reconstruction followed by radiation therapy. (A) 52-year-old patient, right nipple sparing mastectomy; 3 years after the end of radiation therapy; (B) 57-year-old patient, right nipple sparing mastectomy; 9 months after the end of radiation therapy; (C) 45-year-old patient, right nipple sparing mastectomy; 6 months after the end of radiation therapy; (D) 55 -year-old patient, left skin sparing mastectomy; 1 year and a half after the end of radiation therapy.

performed.

In case of two-staged implant reconstruction, the optimal timing of radiation therapy administration has to be decided. Several studies demonstrated higher rates of implant loss, ranging from $32 \%$ to $40 \%$, when radiation was delivered to the tissue expander when compared to radiation directed to definitive implant (35). Also, Cordeiro et al. found higher implant loss rates when radiation therapy was applied to tissue expander but worse aesthetic results and higher capsular contracture rates when it was applied to definitive implants (36). Interestingly, a prospective study performed by the Mastectomy Reconstruction Outcomes Consortium (MROC) found no significant difference in major complication rates between tissue-expander versus implant-directed radiotherapy and reported an overall failure rate of $10 \%$ (37).
In fact, positioning a tissue expander or a definitive prosthesis under the pectoralis major and serratus muscle and then proceeding to a radiation therapy involves a significant fibrotic reaction and shortening of these structures. Therefore, the underlying device is elevated from the original position, the inframammary fold is cephalized and the implant pocket starts to contract.

The introduction of ADM as a completion of subpectoral pocket led to an improvement of aesthetic result and a reduction of capsular contracture incidence. At the same time, some authors proposed to use ADM in reconstructive revisionary surgery with the theoretic purpose of reducing capsular contracture recurrence (38). Nevertheless, while Seth and colleagues did not observe any difference in complication rate utilizing ADM in IBR in comparison to total submuscular implantation in the setting of PMRT, 
Spear observed less reconstruction failures in $\mathrm{ADM}$-assisted IBR after PMRT (19,39). In animal studies, ADM did not suffer any adverse consequence by radiotherapy, although the study of Myckatyn on human biopsy specimens reported an attenuating effect of PMRT on scaffold integration. From the clinical point of view, the contrasting remarks of the various authors left unanswered the question if the use of ADM in implant-based submuscular reconstruction can provide any protection against harmful effects of PMRT (40-42).

The use of ADM in IBR, intended only as an inferolateral extension of the pectoralis major muscle, left the implant substantially submuscular, with analogous drawbacks when compared to traditional subpectoral technique. Moreover, as the fundamental interaction between the implant and the surrounding tissues, remained largely the same, it is not surprising that the risk of highgrade capsular contracture was substantially unmodified.

In recent years, the opportunity of a complete implant coverage by an ADM allowed to perform a muscle-sparing prepectoral reconstruction. In addition to minimization of patient morbidity and preservation of anatomical structures, the implant is positioned in the original site of the mammary gland, obtaining soft and natural aesthetic results. This relatively new technique began to undergo PMRT and Sigalove (18) observed 34 one and two-step PPBR in which PMRT seems to be well-tolerated (2.9\% implant loss, significant capsular contracture $0 \%$, reoperation rate $2.9 \%$ ). On the other hand, in the study by Spear et al. (19) which considers 56 ADM two-stage PPBR, 21\% implant loss and $61 \%$ significant capsular contracture were observed.

In our casistic, apart from a slightly higher rate of capsular contracture, we did not register significant differences in complication and failure rates between PMRT patients and not radiated ones. Moreover, differently from other authors, we ascertained in $85.7 \%$ of radiated patients a surprising stability of softness and shape of reconstruction without fat grafting. This latter procedure has been reserved to the three cases who developed capsular contracture. Even if many authors perform fat grafting systematically 3-6 months after PMRT to improve aesthetic result, in our experience we obtained optimal results even without performing it (BREAST-Q, 86.8 \pm 13.9 ) (20).

The favourable outcomes observed in our study may be related to the protective effect of ADM against capsular contracture (38). From a histopathological point of view, $\mathrm{ADM}$ diminishes inflammatory and fibrotic response that lead to pathologic capsule formation, creating a thinner and less prone to myofibroblasts ingrowth capsule (43). Special attention should be paid to begin PMRT after tissue healing and $\mathrm{ADM}$ integration being well underway, in order to minimize the risk of side effects.

The limitations of our study are its retrospective nature, the small number of patients undergone RT and the relatively short-term follow-up. Further follow-up with additional BREAST-Q administration should be of great interest, in order to observe any possible RT-induced longterm complication. Moreover, our promising outcomes warrant further studies to assess if the total wrapping of prostheses with porcine ADM really protects the stability of reconstruction in PMRT setting. Finally, the intensity of radiation effects on the reconstructed breast is probably not only attributable to the kind of reconstructive surgery, but also to the variables of radiotherapy technique. Therefore, further studies are desirable to investigate side effects of each single scheme of treatment on implant-based reconstruction.

\section{Conclusions}

In our experience one-step PPBR with porcine ADM followed by PMRT seems to be well tolerated, with no significant risk of adverse outcomes, at least in the shortterm follow-up. As this technique does not involve muscular structures, the adverse effects of PMRT on pectoralis major muscle, as fibrosis and shortening, do not influence the stability of implant pocket. In this way, also the incidence of capsular contracture is lower than usually observed in submuscular reconstructions submitted to PMRT. Moreover, also reconstruction failure rate is significantly lower, when compared to the literature, suggesting a protective effect due to ADM integration with subcutaneous tissue. For these reasons, we recommend to all eligible patients the one-step prepectoral porcine-ADM implant breast reconstruction as the preferable technique even in PMRT perspective. Obviously, longer follow-up is needed to better understand the trend of patients undergone PPBR followed by PMRT.

\section{Acknowledgments}

Funding: None.

\section{Footnote}

Conflicts of Interest: All authors have completed the ICMJE 
uniform disclosure form (available at http://dx.doi. org/10.21037/gs.2020.01.16). The authors have no conflicts of interest to declare.

Ethical Statement: The authors are accountable for all aspects of the work in ensuring that questions related to the accuracy or integrity of any part of the work are appropriately investigated and resolved. The research protocol of the study was approved by the local Ethics Committee and patients gave written informed consent.

Open Access Statement: This is an Open Access article distributed in accordance with the Creative Commons Attribution-NonCommercial-NoDerivs 4.0 International License (CC BY-NC-ND 4.0), which permits the noncommercial replication and distribution of the article with the strict proviso that no changes or edits are made and the original work is properly cited (including links to both the formal publication through the relevant DOI and the license). See: https://creativecommons.org/licenses/by-nc-nd/4.0/.

\section{References}

1. Nedumpara T, Jonker L, Williams MR. Impact of immediate breast reconstruction on breast cancer recurrence and survival. Breast 2011;20:437-43.

2. Albornoz CR, Bach PB, Mehrara BJ, et al. A paradigm shift in U.S. breast reconstruction: increasing implant rates. Plast Reconstr Surg 2013;131:15-23.

3. Carlson RW, Allred DC, Anderson BO, et al. NCCN Breast Cancer Clinical Practice Guidelines Panel. Breast cancer. Clinical practice guidelines in oncology. J Natl Compr Canc Netw 2009;7:122-92.

4. Nelson JA, Disa JJ. Breast Reconstruction and Radiation Therapy: An Update. Plast Reconstr Surg 2017;140:60S-8S.

5. Tendulkar RD, Rehman S, Shukla ME, et al. Impact of postmastectomy radiation on locoregional recurrence in breast cancer patients with 1-3 positive lymph nodes treated with modern systemic therapy. Int J Radiat Oncol Biol Phys 2012;83:e577-81.

6. Albornoz CR, Matros E, McCarthy CM, et al. Implant breast reconstruction and radiation: a multicenter analysis of long-term health-related quality of life and satisfaction. Ann Surg Oncol 2014;21:2159-64.

7. Barry M, Kell MR. Radiotherapy and breast reconstruction: a meta-analysis. Breast Cancer Res Treat
2011;127:15-22.

8. Jhaveri JD, Rush SC, Kostroff K, et al. Clinical outcomes of postmastectomy radiation therapy after immediate breast reconstruction. Int J Radiat Oncol Biol Phys 2008;72:859-65.

9. Magill LJ, Robertson FP, Jell G, et al. Determining the outcomes of post-mastectomy radiation therapy delivered to the definitive implant in patients undergoing oneand two-stage implant-based breast reconstruction: A systematic review and meta-analysis. J Plast Reconstr Aesthet Surg 2017;70:1329-35.

10. Clemens MW, Kronowitz SJ. Current perspectives on radiation therapy in autologous and prosthetic breast reconstruction. Gland Surg 2015;4:222-31.

11. Eriksson M, Anveden L, Celebioglu F, et al. Radiotherapy in implant-based immediate breast reconstruction: risk factors, surgical outcomes, and patient-reported outcome measures in a large Swedish multicenter cohort. Breast Cancer Res Treat 2013;142:591-601.

12. Momoh AO, Ahmed R, Kelley BP, et al. A systematic review of complications of implant-based breast reconstruction with prereconstruction and postreconstruction radiotherapy. Ann Surg Oncol 2014;21:118-24.

13. Yu P. Breast reconstruction at the MD Anderson Cancer Center. Gland Surg 2016;5:416-21.

14. Mohiuddin W, Chevrollier GS, Greaney PJ Jr, et al. Optimizing Results of Postmastectomy Radiation Therapy Utilizing the Latissimus Dorsi Flap and Tissue Expander Technique: A Single-Center Experience. Eplasty 2017;17:e40.

15. Reitsamer R, Peintinger F. Prepectoral implant placement and complete coverage with porcine acellular dermal matrix: a new technique for direct-to-implant breast reconstruction after nipple-sparing mastectomy. J Plast Reconstr Aesthet Surg 2015;68:162-7.

16. Berna G, Cawthorn SJ, Papaccio G, et al. Evaluation of a novel breast reconstruction technique using the Braxon ${ }^{\circledR}$ acellular dermal matrix: a new muscle-sparing breast reconstruction. ANZ J Surg 2017;87:493-8.

17. Cattelani L, Polotto S, Arcuri MF, et al. One-Step Prepectoral Breast Reconstruction With Dermal MatrixCovered Implant Compared to Submuscular Implantation: Functional and Cost Evaluation. Clin Breast Cancer 2018;18:e703-11.

18. Sigalove S. Prepectoral breast reconstruction and radiotherapy-a closer look. Gland Surg 2019;8: 67-74. 
19. Spear SL, Seruya M, Rao SS, et al. Two-stage prosthetic breast reconstruction using AlloDerm including outcomes of different timings of radiotherapy. Plast Reconstr Surg 2012;130:1-9.

20. Sbitany H, Gomez-Sanchez C, Piper M, et al. Prepectoral Breast Reconstruction in the Setting of Postmastectomy Radiation Therapy: An Assessment of Clinical Outcomes and Benefits. Plast Reconstr Surg 2019;143:10-20.

21. Wallgren A, Bonetti M, Gelber RD, et al. Risk factors for locoregional recurrence among breast cancer patients: results from International Breast Cancer Study Group Trials I through VII. J Clin Oncol 2003;21:1205-13.

22. Truong PT, Olivotto IA, Kader HA, et al. Selecting breast cancer patients with T1-T2 tumors and one to three positive axillary nodes at high postmastectomy locoregional recurrence risk for adjuvant radiotherapy. Int J Radiat Oncol Biol Phys 2005;61:1337-47.

23. Macdonald SM, Abi-Raad R, Alm El-Din MA, et al. Chest wall radiotherapy: middle ground for treatment of patients with one to three positive lymph nodes after mastectomy. Int J Radiat Oncol Biol Phys 2009;75:1297-303.

24. Chadha M, Portenoy J, Boolbol SK, et al. Is there a role for postmastectomy radiation therapy in ductal carcinoma in situ? Int J Surg Oncol 2012;2012:423520.

25. Chan LW, Rabban J, Hwang ES, et al. Is radiation indicated in patients with ductal carcinoma in situ and close or positive mastectomy margins? Int J Radiat Oncol Biol Phys 2011;80:25-30.

26. Childs SK, Chen YH, Duggan MM, et al. Impact of margin status on local recurrence after mastectomy for ductal carcinoma in situ. Int J Radiat Oncol Biol Phys 2013;85:948-52.

27. American Society of Plastic Surgeons. 2016 Plastic Surgery Statistics Report. Available online: https://www. plasticsurgery.org/documents/News/Statistics/2016/ plastic-surgery-statistics-full-report-2016.pdf

28. Clarke M, Collins R, Darby S, et al. Early Breast Cancer Trialists' Collaborative Group (EBCTCG). Effects of radiotherapy and of differences in the extent of surgery for early breast cancer on local recurrence and 15-year survival: an overview of the randomised trials. Lancet 2005;366:2087-106.

29. Tendulkar RD, Rehman S, Shukla ME, et al. Impact of postmastectomy radiation on locoregional recurrence in breast cancer patients with 1-3 positive lymph nodes treated with modern systemic therapy. Int J Radiat Oncol Biol Phys 2012;83:e577-81.
30. Poortmans PM, Collette S, Kirkove C, et al. EORTC Radiation Oncology and Breast Cancer Groups. Internal Mammary and Medial Supraclavicular Irradiation in Breast Cancer. N Engl J Med 2015;373:317-27.

31. Berry T, Brooks S, Sydow N, et al. Complication rates of radiation on tissue expander and autologous tissue breast reconstruction. Ann Surg Oncol 2010;17:202-10.

32. Clemens MW, Kronowitz SJ. Acellular dermal matrix in irradiated tissue expander/implant-based breast reconstruction: evidence-based review. Plast Reconstr Surg2012;130:27S-34S.

33. Lam TC, Hsieh F, Boyages J. The effects of postmastectomy adjuvant radiotherapy on immediate twostage prosthetic breast reconstruction: a systematic review. Plast Reconstr Surg 2013;132:511-8.

34. Verma V, Shah C, Mehta MP. Clinical Outcomes and Toxicity of Proton Radiotherapy for Breast Cancer. Clin Breast Cancer 2016;16:145-54.

35. Santosa KB, Chen X, Qi J, et al. Postmastectomy Radiation Therapy and Two-Stage Implant-Based Breast Reconstruction: Is There a Better Time to Irradiate? Plast Reconstr Surg 2016;138:761-9.

36. Cordeiro PG, Albornoz CR, McCormick B, et al. What is the optimum timing of postmastectomy radiotherapy in two-stage prosthetic reconstruction: radiation to the tissue expander or permanent implant? Plast Reconstr Surg 2015;135:1509-17.

37. Recht A, Comen EA, Fine RE, et al. Postmastectomy Radiotherapy: An American Society of Clinical Oncology, American Society for Radiation Oncology, and Society of Surgical Oncology Focused Guideline Update. Pract Radiat Oncol 2016;6:e219-34.

38. Cheng A, Lakhiani C, Saint-Cyr M. Treatment of capsular contracture using complete implant coverage by acellular dermal matrix: a novel technique. Plast Reconstr Surg 2013;132:519-29.

39. Seth AK, Hirsch EM, Fine NA, et al. Utility of acellular dermis-assisted breast reconstruction in the setting of radiation: a comparative analysis. Plast Reconstr Surg 2012;130:750-8.

40. Dubin MG, Feldman M, Ibrahim HZ, et al. Allograft dermal implant (AlloDerm) in a previously irradiated field. Laryngoscope 2000;110:934-7.

41. Ibrahim HZ, Kwiatkowski TJ, Montone KT, et al. Effects of external beam radiation on the allograft dermal implant. Otolaryngol Head Neck Surg 2000;122:189-94.

42. Myckatyn TM, Cavallo JA, Sharma K, et al. The impact 
of chemotherapy and radiation therapy on the remodeling of acellular dermal matrices in staged, prosthetic breast reconstruction. Plast Reconstr Surg 2015;135:43e-57e.

Cite this article as: Polotto S, Bergamini ML, Pedrazzi G, Arcuri MF, Gussago F, Cattelani L. One-step prepectoral breast reconstruction with porcine dermal matrix-covered implant: a protective technique improving the outcome in postmastectomy radiation therapy setting. Gland Surg 2020;9(2):219228. doi: 10.21037 /gs.2020.01.16
43. Chopra K, Buckingham B, Matthews J, et al. Acellular dermal matrix reduces capsule formation in two-stage breast reconstruction. Int Wound J 2017;14:414-9. 